\title{
Effect of Negative Pressure Therapy versus Polarized Light Therapy on Chronic Wound Healing
}

\author{
RANA M.M. ELATTAR, M.Sc.*; INTSAR S. WAKED, Ph.D.*; MOHAMED B.I. BAYOUMI, Ph.D.* and \\ ASHRAF E.M. ELSEBAIE, M.D.**
}

The Department of Surgery, Faculties of Physical Therapy* and Medicine**, Cairo University

\begin{abstract}
Background: Chronic wounds are wounds that have failed to proceed through the normal process of healing. There are varying etiologies of chronic wounds, which all create a burden upon the health care system.
\end{abstract}

Aim of Study: The aim of this study was to investigate the difference in the effect between negative pressure therapy and polarized light therapy on chronic wound healing.

Patients and Methods: Thirty patients were diagnosed by a physician as chronic wound patients (grade 2 and 3). Their age ranged from 45 to 65 years. Patientswere selected from Cairo University Hospitals. They were distributed randomly into two groups (A, B) equal in numbers. Group A received negative pressure therapy daily with dressings changes 3 times a week with the traditional medical treatment for 6 weeks. Group B received polarized light therapy for $10 \mathrm{~min} 3$ times aweek with the traditional medical treatment for 6 weeks. Wound surface area and wound volume were assessed by tracing method and saline respectively pretreatment, 3 weeks and 6 weeks after treatment. The study was carried out from July 2020 to October 2020.

Results: There were no significant difference in wound surface area and wound volume between groups pre-treatment $(p>0.05)$. Comparison between both groups post-treatment revealed a non-significant difference in wound surface area and wound volume at post I $(p>0.05)$; however, there were a significant decrease in wound surface area $(p=0.02)$ and wound volume $(p=0.01)$ of group A compared with that of group B at post II.

Conclusion: These results suggested that negative pressure therapy was more effective than polarized light therapy in reducing surface area and wound volume of chronic wound.

Key Words: Chronic wound - Wound healing - Negative pressure therapy - Polarized light therapy.

Correspondence to: Dr. Rana M.M. Elattar, E-Mail: ranaelattar8@gmail.com

\section{Introduction}

CHRONIC wounds are an importantcause of morbiditythat lead to considerable disability and associated with increased rate ofmortality. Therefore, they have a significant effect on public health and the expenditure of health care resources [1]

The prevalence rate for chronic wounds in developed countries is $1 \%$ to $2 \%$ of the general population [2].

The Wound Healing Society classifies causes ofchronic wounds into four categories: Diabetic ulcers, pressure ulcers, venous ulcers and arterial insufficiency ulcers [3].

Wound healing as a normal biological process is achieved through four precisely and highly programmed phases: Hemostasis, inflammation, proliferation and remodeling. For a wound to heal successfully, all four phases must occur in the proper sequence and time frame. Many factors can interfere with one or more phases of this process, thus causing improper or impaired wound healing [4].

Negativepressure therapy collects high volumes of wound exudate and is thought to decrease the frequency of dressing changes by keeping wounds clean, and reducing odour. It is also suggested that the application of suction to the wound promotes healing by the approximating together of wound edges, increasing blood supply, and removing infectious material. NPWT might exert a beneficial effect through preventing unnecessary dressing changes and repeated exposure of the wound to external environment [5]. 
Bioptron light therapy stimulate the endogenous purification by removal of cell debris andinfectious microorganisms via the following; increasing stimulation of macrophages, increasing bacterial phagocytosis activity and bacterial phagocytosis capacity by increasing formation of scavenger cells, increasing stimulation of neutrophils, increasing number of neutrophils and phagocytosis activity [6] .

\section{Patients and Methods}

\section{Subjects:}

Thirty patients were diagnosed by a physician as chronic wound patients (grade 2 and 3), they were selectedfrom Cairo University Hospitals. Their age ranged from 45 to 65 years. They were distributed randomly into two groups (A, B) equal in numbers. Group A received negative pressure therapy daily with dressings changes 3 times a week with the traditional medical treatment for 6 weeks. Group B received polarized light therapy for 10min, 3 times a week with the traditional medical treatment for 6 weeks. Wound surface area and wound volume were assessed by tracing method and saline respectively pretreatment, 3 weeks and 6 weeks after treatment. The inclusion criteria were; patients of both sexes, subject's age ranged between 45 and 65 years, all patients entered the study having their informed consent, all patients were assessed by a physician before starting the study procedure and all patients suffered from chronic wounds (stage 2 and 3). The current study excluded the following patients; patients with acute wounds, patients with burn wound injuries or malignancy in the wound. After ethical approval, thirty patients were selected from Cairo University Hospitals, Cairo, Egypt. The study was conducted from July 2020 to October 2020.

\section{Material:}

Negative pressure therapy device; polarized light therapy device; Saline and graded syringe were used for wound volume measurement; Transparent metric paper was used for wound surface area; plinth for the patient; pillows to support the patients; chair for the therapist; disposable clean plastic gloves; alcohol and some cotton to clean area before the treatment and the treatment performed in quiet and air conditional room.

\section{Procedures:}

\section{Group (A) negative pressure application:}

- Firstly, the parameters of NPWT device should be suited with negative pressure of $125 \mathrm{mmHg}$, with duration of five minute on and two minute off.
- The dressing was applied away from the boundaries of wound about $2-3 \mathrm{~mm}$. The dressing used was spongy dressing to be suitable to the device.

- Sterilized catheter was inserted into the dressing.

- The catheter was connected into the negative pressure device and the treatment was started.

Group (B) polarized light therapy:

- The patient was positioned in a comfortable position.

- Wound should be cleaned at first by saline and betadine.

- Set theparameters of treatmentof PLT $\left(2.4 \mathrm{j} / \mathrm{cm}^{2}\right)$.

- Point the light beam at the area to be treated, holding the device at right angle perpendicular to the surface of the wound and maintaining a distance of $10 \mathrm{~cm}$ from the surface of the wound and applying the PLT for about 10 minute.

- Frequency of application: Applied 3 times per week for 6 weeks.

- The device was unpluged after use and it was advisable to prolong the PLT for one or two weeks if wound closure occured before the end of the treatmentin order to strengthen the treated area.

\section{Statistical analysis:}

Descriptive statistics and unpaired $t$-test were conducted for comparison of age between both groups. Chi-squared test was conducted for comparison of sex and ulcer type distribution between groups. Normal distribution of data was checked using the Shapiro-Wilk test for all variables. Levene's test for homogeneity of variances was conducted to test the homogeneity between groups. Unpaired $t$-test was conducted to compare the mean values of wound surface area and wound volume between groups. ANOVA with repeated measures test was conducted for comparison between pre, post I, and post II measurements of mean values of wound surface area and wound volume in each group. The level of significance for all statistical tests was set at $p<0.05$. All statistical analysis was conducted through the Statistical Package for Social Studies (SPSS) version 25 for windows (IBM SPSS, Chicago, IL, USA).

\section{Results}

\section{Subject characteristics:}

Table (1) showed the subject characteristics of the group A and B. There was no significant difference between both groups in the mean age ( $p>$ 0.05 ). There was no significant difference between groups in sex and ulcer type distribution $(p>0.05)$. 
Effect of treatment on wound surface area and volume:

\section{- Within group comparison:}

There were a significant decrease in wound surface area and wound volume of group A and B at post II compared with that pre-treatment and at post I $(p<0.001)$. Also, there were a significant decrease in wound surface area and wound volume of group A and B at post I compared with that pretreatment $(p<0.001)$ (Table 2$)$, Figs. $(1,2)$.

In group A, the wound surface area decreased by $34.66 \%$ at post I and by $70.78 \%$ at post II while the wound volume decreased by $38.26 \%$ at post I and by $71.67 \%$ at post II. In group B, the wound surface area decreased by $25.58 \%$ at post I and by $54.25 \%$ at post II while the wound volume decreased by $30.27 \%$ at post I and by $58.37 \%$ at post II.

\section{- Between groups comparison:}

There were no significant difference in wound surface area and wound volume between groups pre-treatment $(p>0.05)$. Comparison between both groups post-treatment revealed a non significant difference in wound surface area and wound volume at post I ( $p>0.05)$; however, there were a significant decrease in wound surface area $(p=0.02)$ and wound volume ( $p=0.01)$ of group A compared with that of group B at post II (Table 2), Figs. $(1,2)$.

Table (1): Comparison of subject characteristics between the group A and B.

\begin{tabular}{lccc}
\hline & \multicolumn{2}{c}{ Mean \pm SD } & $\begin{array}{c}p^{-} \\
\text {value }\end{array}$ \\
\cline { 2 - 3 } & Group A & Group B & \\
\hline Age (years) & $55.53 \pm 5.04$ & $55.2 \pm 7.46$ & 0.88 \\
Sex: & & & \\
$\quad$ Females & $6(40 \%)$ & $7(47 \%)$ & 0.71 \\
$\quad$ Males & $9(60 \%)$ & $8(53 \%)$ & \\
Ulcer type: & & & \\
$\quad$ Diabetic & $6(40 \%)$ & $7(47 \%)$ & 0.89 \\
Pressure & $4(27 \%)$ & $3(20 \%)$ & \\
Venous & $5(33 \%)$ & $5(33 \%)$ & \\
\hline
\end{tabular}

SD: Standard Deviation.

Table (2): Mean wound surface area and volume at pre-treatment, post I and post II of group A and B.

\begin{tabular}{|c|c|c|c|c|c|c|}
\hline & \multirow{2}{*}{$\begin{array}{c}\text { Pre-treatment } \\
\text { Mean } \pm \text { SD }\end{array}$} & \multirow{2}{*}{$\begin{array}{c}\text { Post I } \\
\text { Mean } \pm \text { SD }\end{array}$} & \multirow{2}{*}{$\begin{array}{c}\text { Post II } \\
\text { Mean } \pm \text { SD }\end{array}$} & \multicolumn{3}{|c|}{$p$-value } \\
\hline & & & & $\begin{array}{l}\text { Pre vs. } \\
\text { Post I }\end{array}$ & $\begin{array}{l}\text { Pre vs. } \\
\text { Post II }\end{array}$ & $\begin{array}{l}\text { Post I vs. } \\
\text { Post II }\end{array}$ \\
\hline \multicolumn{7}{|c|}{ Wound surface area $\left(\mathrm{cm}^{2}\right)$ : } \\
\hline Group A & $17.11 \pm 6.35$ & $11.18 \pm 3.46$ & $5 \pm 1.76$ & 0.001 & 0.001 & 0.001 \\
\hline Group B & $\begin{array}{l}16.46 \pm 6.52 \\
p=0.78\end{array}$ & $\begin{array}{l}12.25 \pm 5.6 \\
p=0.53\end{array}$ & $\begin{array}{l}7.53 \pm 3.75 \\
p=0.02\end{array}$ & 0.001 & 0.001 & 0.001 \\
\hline \multicolumn{7}{|c|}{ Wound volume $\left(\mathrm{cm}^{2}\right)$ : } \\
\hline Group A & $8.26 \pm 3.07$ & $5.1 \pm 1.91$ & $5.46 \pm 2$ & 0.001 & 0.001 & 0.001 \\
\hline Group B & $\begin{array}{l}7.83 \pm 2.37 \\
p=0.66\end{array}$ & $\begin{array}{l}2.34 \pm 0.89 \\
p=0.61\end{array}$ & $\begin{array}{l}3.26 \pm 1.03 \\
p=0.01\end{array}$ & 0.001 & 0.001 & 0.001 \\
\hline
\end{tabular}

SD: Standard Deviation. $p$-value: Level of significance.

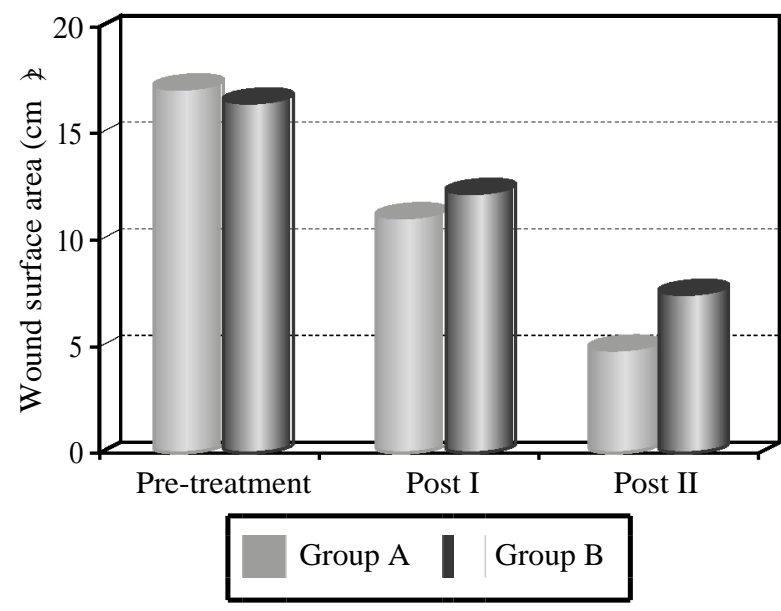

Fig. (1): Mean wound surface area at pre-treatment, post I and post II of group A and B.

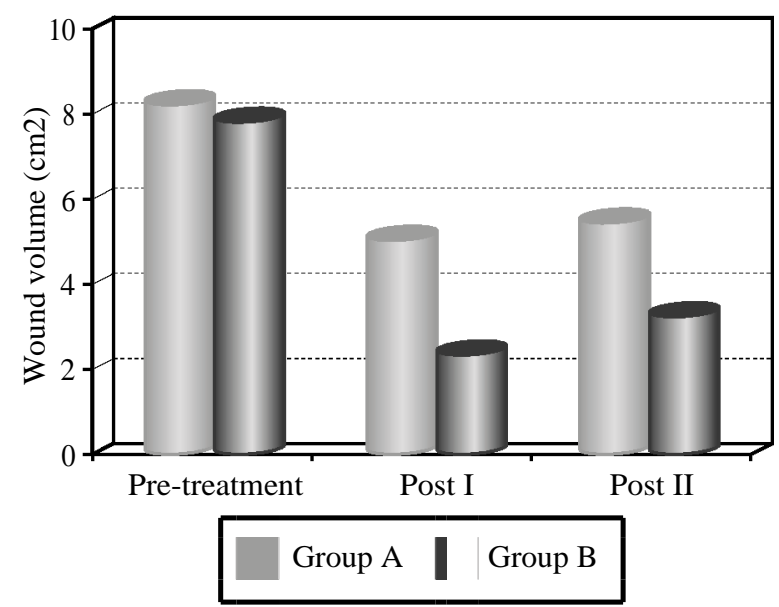

Fig. (2): Mean wound volume at pre-treatment, post I and post II of group A and B. 
(A)

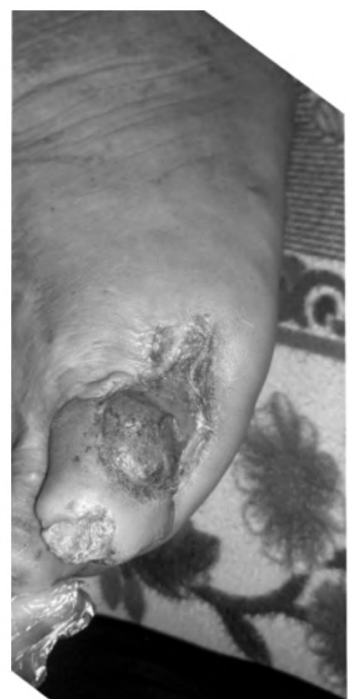

(B)

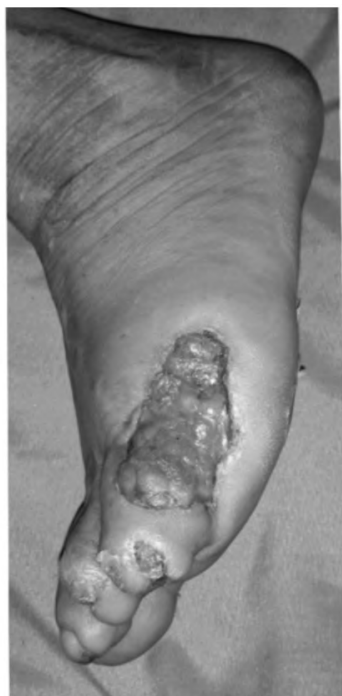

(C)

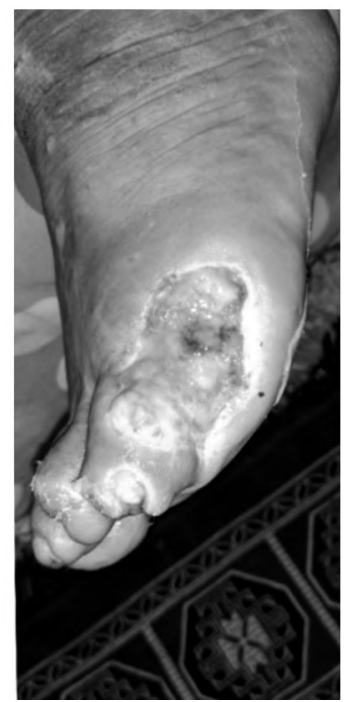

Fig. (3): Changes in wound healing; pre-treatment (A), after 3 weeks (B), and after 6 weeks (C) of treatment using Polarized Light Therapy.

(A)

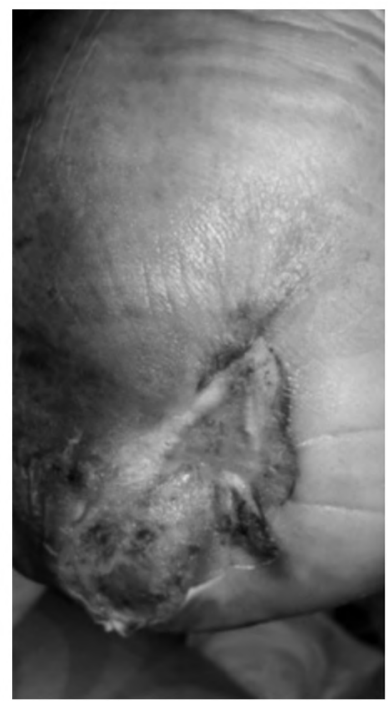

(B)

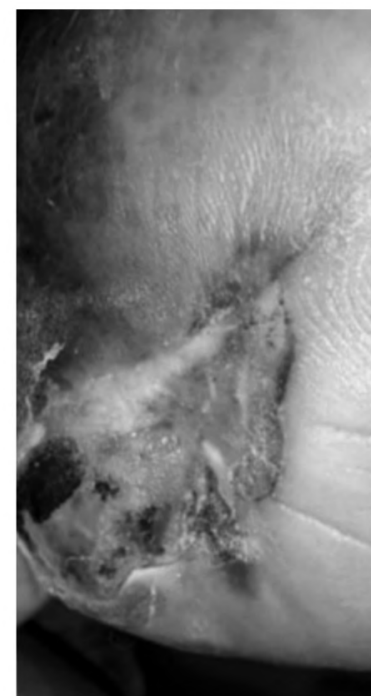

(C)

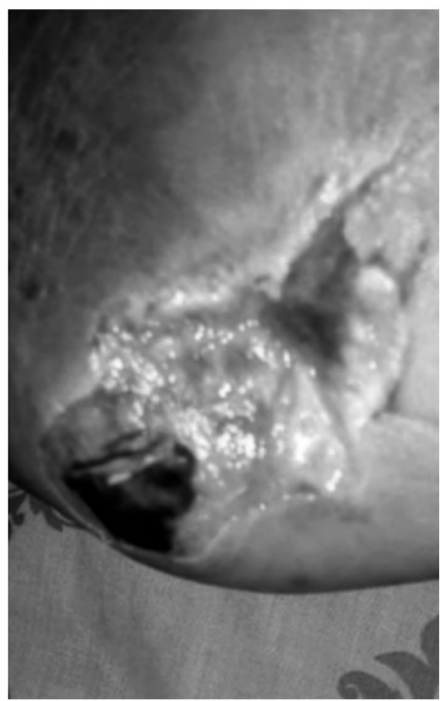

Fig. (4): Changes in wound healing; pre-treatment (A), after 3 weeks (B) and after 6 weeks (C) of treatment using Negative Pressure Therapy.

\section{Discussion}

The purpose of this study was to investigate the effect of negative pressure versus polarized light on healing of chronic wounds. Thirty patients with chronic wounds participated in this study, they were distributed randomly into two groups (A, B) equal in numbers. Group A received negative pressure therapy while group $\mathrm{B}$ received polarized light therapy.

There were no significant difference in wound surface area and wound volume between groups pre-treatment $(p>0.05)$. Comparison between both groups post-treatment revealed a non significant difference in wound surface area and wound volume at post I ( $p>0.05)$; however, there were a significant decrease in wound surface area $(p=0.02)$ and wound volume ( $p=0.01)$ of group A compared with that of group B at post II.

From the previously mentioned results, it is clear that the improvement in healing of chronic wounds in group A and group B is associated with significant decrease in wound surface area and volume.

This improvement in healing of chronic wounds in group A more than group B may be attributed to the fact that NPWT collects high volumes of wound exudate and is thought to reduce the frequency of dressing changes by keeping anatomically challenging wounds clean, and reducing odour. 
It is suggested that wound cleansing is an intrinsic element of wound management. It is performed to remove surface contaminants, bacteria, non-viable tissue (dead or dying tissue) and excess exudate (wound fluid) from the wound bed and surrounding skin. Cleansing is thought to be an effective way to remove inflammatory stimulants and local barriers to wound healing from the wound bed therefore promoting healing.

\section{Our study results confirm the results of the previous studies:}

Kayala et al., [7] reported that NPWT produced significant improvement in wound depth and surface area in patient with bedsores compared to traditional gauze dressings.

Bazaliński et al., [8] concluded that NPWT can successfully be used in the process of cleansing an infected pressure wound to safely remove exudate, minimize local inflammation and increasing granulation tissue formation.

Liu et al., [9] performed a systematic review and metaanalysisto compare between NPWT and traditional dressing in patients with diabetic foot ulcers and found that NPWT had a higher rate of complete healing of ulcers, shorter healing time greater reduction in ulcer area and depth fewer amputation with no incidence of adverse effect.

Medenica and Lens, [10] study results shown that all ulcers except one $(99 \%)$ had a positive value for the change in healing area at the end of the four weeks, the total number of 73 leg ulcers recorded at the beginning of the study was reduced to 51 at the end of the four weeks $(p<0.01)$. The decrease in wound surface area following the treatment was statistically significant (mean 57.15\%: SD: $31.87 \%$ : $p<0.01$ ). They concluded that polarized, polychoromatic light therapy applied as monotherapy was associated with positive healing rates in patients with venous leg ulcers.

Durovi'c et al., [11] found that After a four-week polarized light therapy 20 patients with stage I-III ulcer had significant improvement in pressure ulcer healing, so it could be useful to apply polarized light in the treatment of pressure ulcers. There were significant differences between the groups at the end of the treatment. The patients in the experimental group had significantly higher improvements in the surface of pressure ulcers, rank of pressure ulcers and total PUSH score than the patients in the control group.

Iordanou et al., [12] reported that the group exposed to light therapy showed statistically sig- nificantly faster epithelialization post-wound compared to controls, as well as better quality of the healing process (although not statistically significantly at all-time points) and concluded that this specific fraction of polarized light seems to have beneficial effects on wound healing, leading to faster epithelialization and qualitatively better wound healing.

From the previous discussion of these results and according to reports of researches in the field related to the present study, it could be concluded that the results of this study support the expectation that both negative pressure therapy and polarized light therapy play an important role in the promotion of healing of chronic wounds but negative pressure therapy is more significant.

\section{Conclusion:}

Based on the scope and findings of this study, it could be concluded that negative pressure therapy was more effective than polarized light therapy on reducing wound surface area and wound volume in chronic wounds.

\section{References}

1- DHARMENDRA B.L. and KUMAR V.: Vacuum-assisted closure of wounds-an effective method for diabetic ulcers. Journal of evolution of medical and dental sciences, 7 (36): 4012-8, 2018.

2- HEYER K., HERBERGER K., PROTZ K., et al.: Epidemiology of chronic wounds in Germany: Analysis of statutory health insurance data. Wound Repair Regen., 24: 434-42, 2016.

3- Wound Healing Society: Chronic wound care guidelines. http://woundheal.org/documents/final pocket guide treatment.aspx. Accessed. 21 Mar., 2016

4- GUO S. and DiPIETRO L.A.: Factors Affecting Wound Healing. Journal of Dental Research, 89 (3): 219-29, 2010.

5- HUANG C., LEAVITT T., BAYER L.R. and ORGILL D.P.: Effect of negative pressure wound therapy on wound healing. Current Problems in Surgery, 51 (7): 301-31, 2014.

6- MONSTREY S., HOEKSEMA H., DEPUYDT K., VAN MAELE G.E.O.R.G.E.S., VAN LANDUYT K. and BLONDEEL P.: The effect of polarized light on wound healing. European Journal of Plastic Surgery, 24 (8): $377-$ $82,2002$.

7- KAYALA R., MANASA K.V. and REDDY M.: Efficacy of negative pressure wound therapy when compared to gauze dressings in the management of bedsores. International Journal of Surgery, 3 (4): 279-81, 2019.

8- BAZALINSKI D., WI ECH P., KACZMARSKA D., SALACINSKA I. and ANDKÓZKA M.: Use of controlled negative pressure in management of phlegmon caused by fulminant complication of pressure wound: A case report. Medicine, 97 (28), 2018. 
9- LIU S., HE C.Z., CAI Y.T., XING Q.P., GUO Y.Z., CHEN Z.L. and YANG L.P.: Evaluation of negative-pressure wound therapy for patients with diabetic foot ulcers: Systematic review and meta-analysis. Therapeutics and clinical risk management, 13: 533, 2017.

10- MEDENICA L. and LENS M.: The use of polarised polychromatic non-coherent light alone as a therapy for venous leg ulceration. Journal of wound care, 12 (1): $37-$ 40, 2003.
11- DUROVIC' A., MARIC’ D., BRDARESKI Z., JEVTIC'M. and -DURDEVIC'S.: The effects of polarized light therapy in pressure ulcer healing. Vojnosanitetskipregled, 65 (12): 906-12, 2008.

12- IORDANOU P., LYKOUDIS E.G., ATHANASIOU A., KONIARIS E., PAPAEVANGELOU M., FATSEA T. and BELLOU P.: Effect of visible and infrared polarized light on the healing process of full-thickness skin wounds: An experimental study. Photomedicine and laser surgery, 27 (2): 261-7, 2009.

\title{
تآثير الضغط السلبى مقابل الضوء المستقطب الهبئ على إلتئام الجروح المزيله
}

\author{
الهدف من الدراسة: آجريت هذه الدراسة لمعرفة تآثير الضفط السلبى مقابل الضوء المستقطب على إلتئام الجروح المزمنه. \\ شـارك فى هذه الدراسة . r مريضاً من الإناث والذكو، وتم تقسيمهم عشوائياً إلى مجموعتين متساويتين فى العدد.

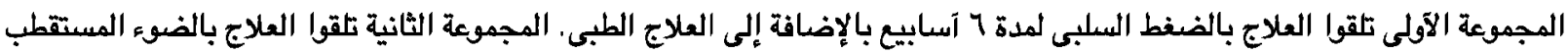

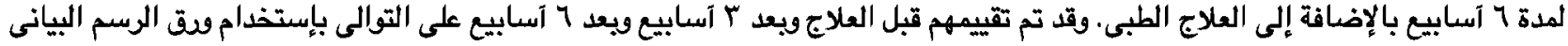

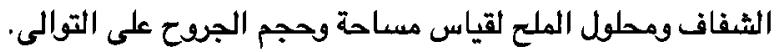

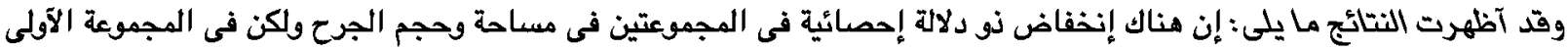

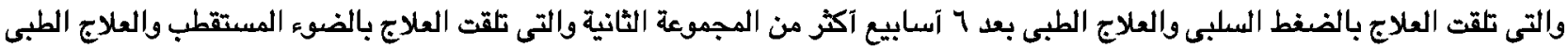

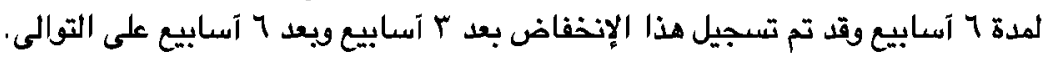 \\ ويعد مناقشة هذه النتائج وتحليلها قد تبين آن الضغط السلبى كان له تآثيراً آفضل وذو دلالة إحصائية فى إلتئام الجروح المزمنة من الضوء

